\title{
Orally available Mn porphyrins with superoxide dismutase and catalase activities
}

\author{
Rosalind A. Rosenthal - Karl D. Huffman - Leslie W. Fisette • \\ Christy A. Damphousse - Wyeth B. Callaway · Bernard Malfroy • \\ Susan R. Doctrow
}

Received: 11 March 2009/Accepted: 18 May 2009/Published online: 6 June 2009

(C) The Author(s) 2009. This article is published with open access at Springerlink.com

\begin{abstract}
Superoxide dismutase/catalase mimetics, such as salen Mn complexes and certain metalloporphyrins, catalytically neutralize reactive oxygen and nitrogen species, which have been implicated in the pathogenesis of many serious diseases. Both classes of mimetic are protective in animal models of oxidative stress. However, only AEOL11207 and EUK-418, two uncharged Mn porphyrins, have been shown to be orally bioavailable. In this study, EUK-418 and several new analogs (the EUK-400 series) were synthesized and shown to exhibit superoxide dismutase, catalase, and peroxidase activities in vitro. Some also protected PC12 cells against staurosporine-induced cell death. All EUK-400 compounds were stable in simulated gastric fluid, and most were substantially more lipophilic than the salen Mn complexes EUK-189 and EUK-207, which lack oral activity. Pharmacokinetics studies
\end{abstract}

Electronic supplementary material The online version of this article (doi:10.1007/s00775-009-0550-4) contains supplementary material, which is available to authorized users.

R. A. Rosenthal · K. D. Huffman - C. A. Damphousse .

S. R. Doctrow $(\square)$

Pulmonary Center, Boston University School of Medicine,

715 Albany St., R-304, Boston, MA 02118, USA

e-mail: sdoctrow@bu.edu

W. B. Callaway

Frontier Scientific, Inc.,

Logan, UT, USA

B. Malfroy

MindSet Rx, Inc.,

Arlington, MA, USA

L. W. Fisette

Proteome Systems, Inc., 6H Gill Street,

Woburn, MA 01801, USA demonstrate the presence of all EUK-400 series compounds in the plasma of rats after oral administration. These EUK-400 series compounds are potential oral therapeutic agents for cellular damage caused by oxidative stress.

Keywords Superoxide dismutase/catalase mimetics . Manganese porphyrins - EUK-400 series compounds . Oxidative stress $\cdot$ Apoptosis

\begin{tabular}{|c|c|}
\hline \multicolumn{2}{|l|}{ Abbreviations } \\
\hline ALS & Amyotrophic lateral sclerosis \\
\hline ABTS & $\begin{array}{l}\text { 2, 2'-Azinobis(3-ethylbenzthiazoline- } \\
\text { 6-sulfonate) diammonium salt }\end{array}$ \\
\hline XTT & $\begin{array}{l}\text { 2,3-Bis(2-methoxy-4-nitro-5-sulfophenyl)- } \\
2 \mathrm{H} \text {-tetrazolium-5-carboxanilide }\end{array}$ \\
\hline AEOL11207 & $\begin{array}{l}\text { 5,15-Bis(methoxycarbonyl)-10,20- } \\
\text { bistrifluoromethylporphyrinato } \\
\text { manganese(III) chloride }\end{array}$ \\
\hline ESI & Electrospray ionization \\
\hline HPLC & High-performance liquid chromatography \\
\hline HRMS & High-resolution mass spectroscopy \\
\hline LC-MS/MS & $\begin{array}{l}\text { Liquid chromatography with tandem mass } \\
\text { spectroscopy }\end{array}$ \\
\hline MnTBAP & $\begin{array}{l}\text { Manganese(III) tetrakis(4-benzoic acid) } \\
\text { porphyrin }\end{array}$ \\
\hline AEOL10150 & $\begin{array}{l}\text { Manganese(III) tetrakis }\left(N, N^{\prime} \text {-diethylimida }\right. \\
\text { zolium-2-yl) porphyrin }\end{array}$ \\
\hline MnTMPyP & $\begin{array}{l}\text { Manganese(III) tetrakis(1-methyl- } \\
\text { 4-pyridyl) porphyrin }\end{array}$ \\
\hline MS & Mass spectroscopy \\
\hline NBT & Nitro blue tetrazolium \\
\hline PBR & Peripheral benzodiazepam receptor \\
\hline RNS & Reactive nitrogen species \\
\hline
\end{tabular}


ROS

SGF

STS

SOD

TLC

\section{Introduction}

An excess of reactive oxygen species (ROS) and reactive nitrogen species (RNS) mediates cumulative damage to tissues by oxidation of DNA and other macromolecules, peroxidation of lipids, and nitration of tyrosine residues. Mitochondrial injury, microvascular damage, and chronic inflammatory events are also associated with the state of oxidative stress. The brain is especially sensitive to oxidative damage owing at least in part to its high rate of $\mathrm{O}_{2}$ consumption and relative lack of antioxidant defenses [1-3]. Oxidative stress has been implicated in a number of neurodegenerative diseases, including Alzheimer's disease, Parkinson's disease, amyotrophic lateral sclerosis (ALS), and Huntington's disease, as well as atherosclerosis, chronic inflammatory disease, rheumatoid arthritis, autoimmune disease, and injury caused by exposure to ionizing radiation $[1,3]$.

Superoxide dismutase (SOD)/catalase mimetics such as salen $\mathrm{Mn}$ complexes and certain metalloporphyrins are synthetic compounds that catalytically mimic both SOD and catalase, neutralizing the ROS superoxide and hydrogen peroxide [4-6]. Some mimetics also neutralize, via peroxidase-like mechanisms, RNS such as peroxynitrite [7-9]. Treatment with salen Mn mimetics (such as EUK189) has been shown to protect against injury due to oxidative stress in animal models of diseases, including Parkinson's disease [10], ALS [11], and Alzheimer's disease [12], and stroke [13]. Treatment with EUK-189 or EUK-207, a cyclized salen Mn complex, prevents ageassociated cognitive impairment in mice [14]. In addition, treatment of mice lacking mitochondrial SOD $(\operatorname{sod} 2-/-)$ with EUK-189 is neuroprotective and increases median life span from 8 to 30 days [15]. Recent evidence also demonstrates that EUK-189 mitigates radiation damage in rat lung [16] and prolongs survival of mice receiving a lethal dose of total body radiation [17].

Metalloporphyrin SOD/catalase mimetics have also been shown to protect against radiation injury [18-23] and CNS disorders [24-27]. Many diseases characterized by oxidative stress are chronic in nature. For such disorders an orally active therapeutic agent would be highly desirable. The salen Mn complexes (EUK-189 and EUK-207) lack oral bioavailability and, like Mn porphyrins, are administered by injection or infusion. Recently Liang et al. [27] described an improved metalloporphyrin, 5,15-bis(methoxycarbonyl)10,20-bistrifluoromethylporphyrinato manganese(III) chloride (AEOL11207), found to be orally active and present in the brains of treated mice. We and our collaborators have also described two orally bioavailable low molecular weight Mn porphyrins called "EUK-418" and "EUK-423" [28] that are also found in the brain and other tissues of mice after oral administration [29]. To our knowledge, no bioavailability data are available for any other Mn porphyrins, including the new lipophilic Mn porphyrin compounds described by Lahaye et al. [30] and Trova et al. [31]. The goal of our study was to develop several new EUK-400 series compounds and characterize all EUK-400 compounds with respect to their catalytic activities, oral bioavailability, and other relevant properties.

\section{Materials and methods}

\section{Materials}

Tissue culture media, sera, and supplements were obtained from Invitrogen (Carlsbad, CA, USA). BD BioCoat collagen-coated plates were purchased from Becton, Dickinson (Franklin Lakes, NJ, USA). Staurosporine (STS; catalog no. 1055 682) and 2,3-bis(2-methoxy-4-nitro-5-sulfophenyl)- $2 H$-tetrazolium-5-carboxanilide (XTT; catalog no. 1 465 015) were obtained from Roche (Indianapolis, IN, USA). Acetonitrile was purchased from J.T. Baker (Phillipsburg, NJ, USA). Formic acid and methanol were from EMD Chemicals (obtained from VWR). Solvents for synthesis were obtained in bulk from Fisher. The 4-tetrahydropyran carboxaldehyde was purchased from Combi-Blocks (San Diego, CA, USA). All other chemicals were obtained from Sigma Chemicals (St Louis, MO, USA).

\section{Animals}

Sprague-Dawley rats were obtained from Charles River Laboratories (Wilmington, MA, USA). Animal studies giving the data in Table 3 were performed at TGA Sciences (Medford, MA, USA). This facility is USDA-registered and AAALAC-accredited, and these studies were supervised by an in-house Institutional Animal Care and Use Committee. Animal studies giving the data in Fig. 3 were performed by Cerep (Redmond, WA, USA). Standard operating procedures related to this work were reviewed and approved by the Cerep Ethics Committee.

Inhibition of STS-induced cell death in PC12 cells

Rat pheochromocytoma (PC12) cells from adrenal gland were purchased from the American Type Culture Collection 
(Rockville, MD, USA; catalog no. CRL 1721). Cells were maintained in RPMI 1640 media with $12.5 \%$ equine serum and $2.5 \%$ fetal bovine serum, $2 \mathrm{mM}$ L-glutamine, and $100 \mathrm{U} \mathrm{ml}^{-1}$ penicillin/streptomycin at $37{ }^{\circ} \mathrm{C}$ with $5 \% \mathrm{CO}_{2}$. For assay, cells were plated at a density of 10,000 cells ml ${ }^{-1}$ on collagen-coated 96-well microtiter plates. Lyophilized STS was reconstituted in ethanol, and the concentration was determined by UV absorption $\left(\varepsilon_{292}=57.38 \mathrm{mM}^{-1} \mathrm{~cm}^{-1}\right)$. STS was added at various concentrations to induce cell death. Test compounds were added together with the STS. Cells were incubated overnight at $37{ }^{\circ} \mathrm{C}, 5 \% \mathrm{CO}_{2}$. After 18 $24 \mathrm{~h}$, test medium was removed, and cell viability was determined using the XTT viability assay [13].

\section{Compound synthesis}

The syntheses of EUK-418 and EUK-423 have been described previously [29]. The synthesis of 5,15 porphyrins (all the EUK-400 compounds except EUK-425) is shown in Scheme 1 . In a typical experiment, 2,2'-dipyrromethane, 1 (100 mmol), prepared as described in [32], and the appropriate aldehyde $(100 \mathrm{mmol})$ were dissolved in 161 dichloromethane in a flask. Argon was bubbled into the solution with stirring for $1 \mathrm{~h}$. The contents were protected from light and trifluoroacetic acid was added $(22 \mathrm{mmol})$ and the mixture was stirred $16 \mathrm{~h}$. 2,3-Dichloro-5,6-dicyanobenzoquinone $(150 \mathrm{mmol})$ was then added, and the mixture was stirred for $1 \mathrm{~h}$. Triethylamine was added $(10 \mathrm{ml})$ and the mixture was stirred $5 \mathrm{~min}$. The porphyrin was purified by column chromatography on silica with elution with dichloromethane. These porphyrins were characterized by ${ }^{1} \mathrm{H}-\mathrm{NMR}$ and thin-layer chromatography (TLC).

Manganese incorporation is shown in Scheme 2 [33]. The 5,15 porphyrin $(1 \mathrm{mmol})$ was dissolved in $100 \mathrm{ml}$ acetic acid. Manganese acetate tetrahydrate $(6 \mathrm{mmol})$ and sodium acetate $(6 \mathrm{mmol})$ were added and the mixture was heated at $100{ }^{\circ} \mathrm{C}$ for $2 \mathrm{~h}$. When the reaction was complete as monitored by TLC, the heat was turned off and the red solution cooled. Dichloromethane $(500 \mathrm{ml})$ was added and

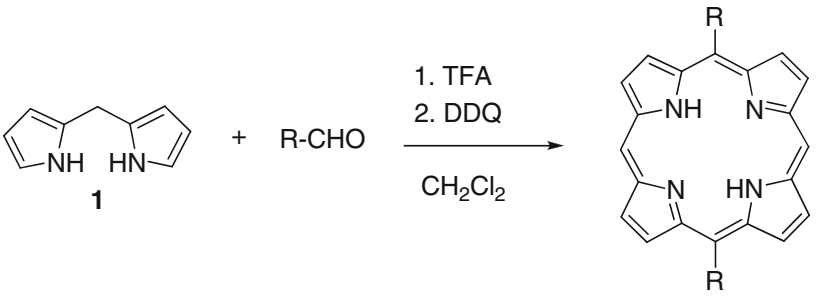

Scheme 1 Synthesis of 5, 15 porphyrin ligands for all EUK-400 compounds except for EUK-425. TFA is trifluoroacetic acid and DDQ is 2,3-dichloro-5,6-dicyanobenzoquinone. Further details are described in Materials and methods

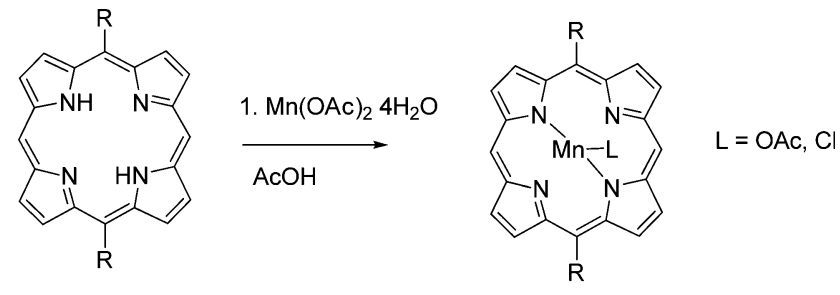

EUK 400 series

Scheme 2 Incorporation of metal to form Mn porphyrin complex for all EUK-400 compounds except for EUK-425. Further details are described in Materials and methods

the organics were extracted with $5 \times 250 \mathrm{ml} \mathrm{H}_{2} \mathrm{O}$ and then $1 \times 50 \mathrm{ml}$ brine. The organic layer was dried over sodium sulfate. The compound was dissolved in dichloromethane and slowly precipitated with hexane to give a copper-colored crystalline solid that was washed with hexane and dried under vacuum overnight. The ligand was presumed to be acetate in the case of a neutral work-up or chloride when the organic phase was washed with $1 \mathrm{~N} \mathrm{HCl}$. The purity and identity of the subsequent $\mathrm{Mn}$ (III) 5,15-disubstituted porphyrins was assessed by TLC, UV-vis spectroscopy, electrospray ionization (ESI)-mass spectroscopy (MS), and high-performance liquid chromatography (HPLC). For TLC screening, compounds were applied to silica plates which were run in $10 \%$ methanol, $20 \%$ ethyl acetate, and $70 \%$ dichloromethane. Samples were considered to be of sufficient purity if there was a single spot of product and no detection of starting materials. (More detailed chromatography information, including retention times in HPLC systems, is given below and in the electronic supplementary material, where chromatograms are shown.) UV-vis spectra were obtained with a Beckmann DU7400 spectrophotometer, using methanol as the solvent. HPLC methods are described below. Elemental analysis, ESI-MS (including methods used), HPLC chromatograms, and absorption spectra of EUK-400 series compounds and multiple reaction monitoring transitions monitored on liquid chromatography with tandem MS (LC-MS/MS) are available online as electronic supplementary material. The compounds synthesized for this work, hereafter referred to by their EUK designation, are summarized in Fig. 1a.

EUK-425, manganese(III) 5,10,15,20-tetraethylporphine acetate, was prepared from 5,10,15,20-tetraethylporphyrin [34] following the method of Meunier and Cosledan [29] as shown in Scheme 3.

The ${ }^{1} \mathrm{H}-\mathrm{NMR}\left(\mathrm{CDCl}_{3}\right)$ data and yield obtained for each unmetallated precursor compound are as follows: precursor to EUK-418-5,15-dicyclopropylporphine, 10.13 (s, 2H), $9.92(\mathrm{~d}, 4 \mathrm{H}), 9.35(\mathrm{~d}, 4 \mathrm{H}), 4.21(\mathrm{tt}, 2 \mathrm{H}), 1.95(\mathrm{dt}, 4 \mathrm{H})$, $1.75(\mathrm{dt}, 4 \mathrm{H}),-2.94(\mathrm{bs}, 2 \mathrm{H})$, yield $56 \%$; precursor to 
Fig. 1 a Structures of EUK400 series compounds. Structures are also given for the related Mn porphyrins 5,15bis(methoxycarbonyl)-10,20bistrifluoromethylporphyrinato manganese(III) chloride (AEOL11207) [27],

manganese(III) tetrakis(4benzoic acid) porphyrin $($ MnTBAP), and manganese(III) tetrakis(1-methyl-4-pyridyl) porphyrin $(M n T M P y P)$ [5]. b Structures of the salen Mn complexes EUK-189 and EUK207. $\mathrm{OAc}$ acetoxy $\left(\mathrm{CH}_{3} \mathrm{COO}\right)$
A

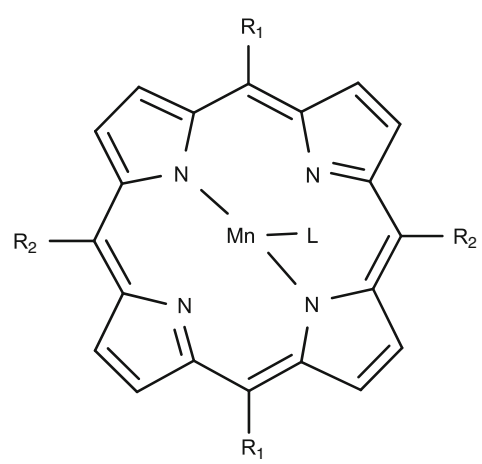

\begin{tabular}{|c|c|c|c|}
\hline EUK- & $\mathbf{L}$ & $\mathbf{R}_{1}$ & $\mathbf{R}_{2}$ \\
\hline 418 & OAc & cyclopropyl & $\mathrm{H}$ \\
\hline 423 & $\mathrm{OAc}$ & phenyl & $\mathrm{H}$ \\
\hline 425 & $\mathrm{OAc}$ & ethyl & same as $R_{1}$ \\
\hline 450 & OAc & $\begin{array}{l}\text { 3,4-methoxy- } \\
\text { phenyl }\end{array}$ & $\mathrm{H}$ \\
\hline 451 & $\mathrm{Cl}$ & $\begin{array}{c}\text { 4-tetra- } \\
\text { hydropyrano }\end{array}$ & $\mathrm{H}$ \\
\hline 452 & $\mathrm{Cl}$ & cyclohexyl & $\mathrm{H}$ \\
\hline 453 & $\mathrm{Cl}$ & propyl & $\mathrm{H}$ \\
\hline AEOL11207 & $\mathrm{Cl}$ & $\mathrm{CO}_{2} \mathrm{CH}_{3}$ & $\mathrm{CF}_{3}$ \\
\hline MnTBAP & $\mathrm{Cl}$ & 4-benzoic acid & same as $R_{1}$ \\
\hline MnTMРyP & $\mathrm{Cl}$ & $\begin{array}{l}\text { 1-methyl-4- } \\
\text { pyridyl }\end{array}$ & same as $R_{1}$ \\
\hline
\end{tabular}

B
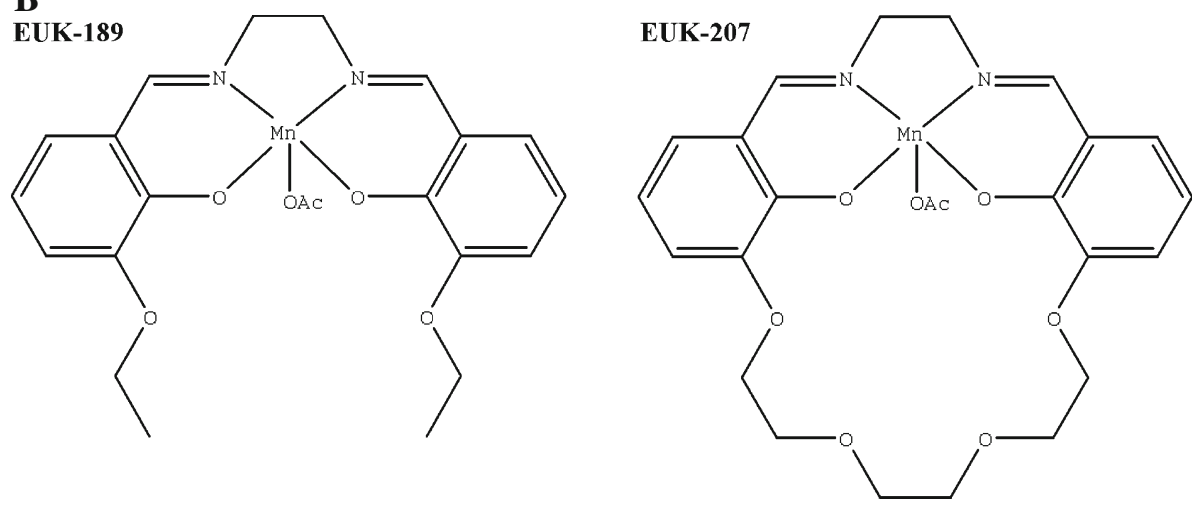

Scheme 3 Synthesis of EUK425 , following the method of Meunier and Cosledan [29]

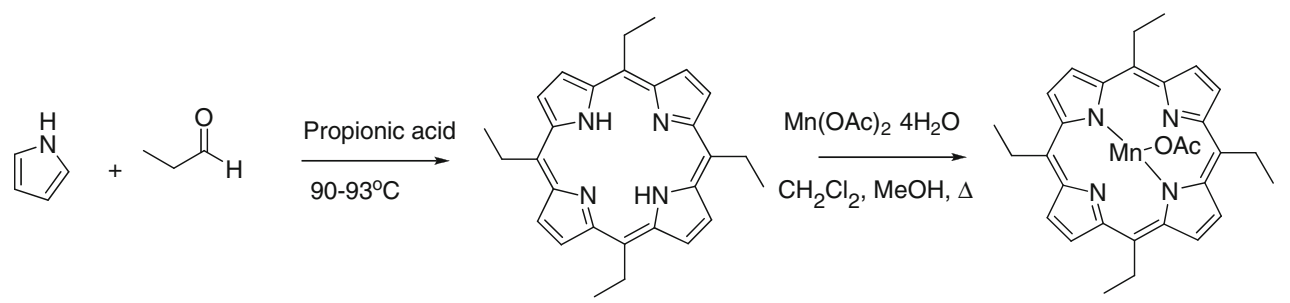

EUK-423-5,15-diphenylporphine, 11.88 (s, 2H), 9.40 (d, $4 \mathrm{H}), 9.09(\mathrm{~d}, 4 \mathrm{H}), 8.28(\mathrm{~m}, 4 \mathrm{H}), 7.82(6 \mathrm{H}),-3.12$ (bs, 2H), yield 63\%; precursor to EUK-450-5,15-(3,4dimethoxyphenyl)porphine, 10.31 (s, 2H), 9.40 (d, 4H), 9.13 (d, 4H), $7.83(\mathrm{~m}, 4 \mathrm{H}), 7.31(\mathrm{~d}, 2 \mathrm{H}), 4.21(\mathrm{~s}, 6 \mathrm{H}), 4.04(\mathrm{~s}, 6 \mathrm{H})$, -3.11 (bs, $2 \mathrm{H}$ ), yield 52\%; precursor to EUK-451-5,15di(4-tetrahydropyranyo)porphine, 10.23 (s, 2H), 9.80 (bd, 4H), $9.44(\mathrm{~d}, 4 \mathrm{H}), 5.48(\mathrm{tt}, 2 \mathrm{H}), 4.53(\mathrm{dd}, 4 \mathrm{H}), 4.12(\mathrm{t}, 4 \mathrm{H})$, 
$3.57(\mathrm{dq}, 4 \mathrm{H}), 2.63(\mathrm{~d}, 4 \mathrm{H}),-2.49$ (bs, $2 \mathrm{H})$, yield $32 \%$; precursor to EUK-452-5,15-dicyclohexylporphine, 10.18 (s, 2H), 9.77 (bs, 4H), $9.40(\mathrm{~d}, 4 \mathrm{H}), 5.22(\mathrm{tt}, 2 \mathrm{H}), 3.12(\mathrm{dq}$, $4 \mathrm{H}), 2.76$ (bd, 4H), 2.30 (dd, 6H), $1.98(\mathrm{~m}, 6 \mathrm{H}),-2.45$ (bs, $2 \mathrm{H}$ ), yield $34 \%$; precursor to EUK-453-5,15-dipropylporphine, $10.17(\mathrm{~s}, 2 \mathrm{H}), 9.58(\mathrm{~d}, 4 \mathrm{H}), 9.41(\mathrm{~d}, 4 \mathrm{H}), 5.00(\mathrm{t}, 4 \mathrm{H})$, $2.57(\mathrm{~h}, 4 \mathrm{H}), 1.33(\mathrm{t}, 6 \mathrm{H}),-2.93(\mathrm{bs}, 2 \mathrm{H})$, yield $25 \%$.

The ESI high-resolution MS (HRMS) and UV-vis data, and the metallation yield obtained for each compound are as follows: EUK-418, manganese(III) 5,15-dicyclopropylporphine acetate, ESI-HRMS: anal. calc. for $\mathrm{C}_{26} \mathrm{H}_{20} \mathrm{~N}_{4} \mathrm{Mn}^{+}$ 443.1068, observed 443.1059, UV-vis: $\lambda_{\max }, \mathrm{nm} ;\left(\varepsilon, \mathrm{M}^{-1}\right.$ $\left.\mathrm{cm}^{-1}\right)$ : $373(40,814), 395(37,382), 462(58,498)$, yield 98\%; EUK-423: manganese(III) 5,15-diphenylporphine acetate, ESI-HRMS: anal. calc. for $\mathrm{C}_{32} \mathrm{H}_{20} \mathrm{~N}_{4} \mathrm{Mn}^{+}$515.1068, observed 515.1071, UV-vis: 372 (66,532), $393(49,164), 459$ (72,914), yield 78\%; EUK-425: manganese(III) 5, 10,15, 20-tetraethylporphine acetate, ESI-HRMS: anal. calc. for $\mathrm{C}_{28} \mathrm{H}_{28} \mathrm{~N}_{4} \mathrm{Mn}^{+}$475.1694, observed 475.1699. UV-vis: 380 $(45,203), 402$ (41,163), $471(58,144)$, yield 36\%; EUK-450: manganese(III) 5,15-di-3,4-dimethoxyphenylporphine acetate, ESI-HRMS: anal. calc. for $\mathrm{C}_{36} \mathrm{H}_{28} \mathrm{~N}_{4} \mathrm{O}_{4} \mathrm{Mn}^{+}$635.1491, observed 615.1503, UV-vis: 373 (45,564), 395 (43,122), 462 (68,535), yield 50\%; EUK-451: manganese(III) 5,15-ditetrahydropyranyoporphine chloride: ESI-HRMS: anal. calc. for $\mathrm{C}_{30} \mathrm{H}_{28} \mathrm{~N}_{4} \mathrm{O}_{2} \mathrm{Mn}^{+}$531.1593, observed 531.158, UV-vis: 372 (48,088), 393 (43,813), 460 (72,370), yield 95\%; EUK-452: manganese(III) 5,15-dicyclohexylporphine chloride, ESI-HRMS: anal. calc. for $\mathrm{C}_{32} \mathrm{H}_{32} \mathrm{~N}_{4} \mathrm{Mn}^{+}$527.2007, observed 527.1993, UV-vis: 374 (44,365), 394 (40,921), 461 (61,952), yield 97\%; EUK-453: manganese(III) 5,15-d ipropylporphine chloride, ESI-HRMS: anal. calc. for $\mathrm{C}_{26} \mathrm{H}_{24}$ $\mathrm{N}_{4} \mathrm{Mn}^{+}$447.1381, observed 447.1383, UV-vis: 374 (49,723), 395 (44,441), $462(54,688)$, yield $95 \%$.

\section{Catalytic activity}

Catalase activity was assayed by measuring the disappearance of hydrogen peroxide in 96-well plates, measured using horseradish peroxidase coupled oxidation of $2,2^{\prime}$ azinobis(3-ethylbenzthiazoline-6-sulfonate) diammonium salt (ABTS). The method was as described in [35], except the initial hydrogen peroxide concentration was $100 \mu \mathrm{M}$, and oxidation of ABTS was monitored at $690 \mathrm{~nm}$ to eliminate interference from porphyrins. SOD activity was measured indirectly in multiwell plates, using xanthine/ xanthine oxidase as the superoxide-generating system and nitro blue tetrazolium (NBT) as the detector. Reduction of NBT was monitored at $550 \mathrm{~nm}$ in a final volume of $0.21 \mathrm{ml}$. The temperature was maintained at $25{ }^{\circ} \mathrm{C}$. The final concentrations of the reagents were as follows: $50 \mathrm{mM}$ sodium phosphate, $\mathrm{pH} 7.8,17.7 \mathrm{mU} \mathrm{ml}^{-1}$ xanthine oxidase, $2,750 \mathrm{U} \mathrm{ml}^{-1}$ catalase, $250 \mu \mathrm{M}$ xanthine, and
$10 \mu \mathrm{M}$ NBT. Another superoxide indicator, cytochrome $c$, generated artifacts in this assay, consistent with the interference observed when using manganese(III) tetrakis (4-benzoic acid) porphyrin (MnTBAP) analogs [31]. One unit of activity was defined as the amount of compound which blocked 50\% NBT reduction under these conditions. Bovine $\mathrm{Cu} / \mathrm{Zn}$ SOD was used as a standard (Sigma S-5395). Controls for the SOD assay include ensuring that the compound does not affect the superoxide-generating reaction, testing solvent alone, and ensuring that the compound does not react independently with NBT. Peroxidase activity was assessed in the presence of hydrogen peroxide with tetramethyl benzidine as the substrate. The final concentrations of the reagents were $5 \mu \mathrm{M}$ sample, $0.2 \mathrm{mM}$ hydrogen peroxide, and $0.225 \mathrm{mM}$ tetramethyl benzidine in a volume of $1.1 \mathrm{ml}$ at a temperature of $27^{\circ} \mathrm{C}$. The reaction was monitored at $655 \mathrm{~nm}$. Controls for the catalase and peroxidase assays include ensuring that the reactions are hydrogen peroxide dependent.

\section{Quantitation of compounds by HPLC}

Samples from simulated gastric fluid (SGF) and octanol partitioning studies were analyzed by HPLC using a Waters model 2695 system equipped with a model 2996 photodiode array detector. A Whatman Partisil 10 ODS-3 (4.6 mm $\times 250 \mathrm{~mm}$ ) column was used. The column was equilibrated with $50 \%$ methanol and $50 \% 100 \mathrm{mM} \mathrm{NaCl}$, and samples were injected in a volume of $50 \mu \mathrm{l}$. All Mn porphyrins except EUK-452 were eluted from the column at $1.0 \mathrm{ml} \mathrm{min}^{-1}$ with a gradient to $80 \%$ methanol over $1 \mathrm{~min}$. EUK-452 was eluted with a gradient to $100 \%$ methanol over $1 \mathrm{~min}$. A wavelength of $458 \mathrm{~nm}$ was used for detection of all EUK-400 series compounds. EUK-189 and EUK-207 compounds were injected similarly onto a column equilibrated with $0 \%$ methanol and $100 \% 100 \mathrm{mM} \mathrm{NaCl}$, and were eluted with a gradient to $60 \%$ methanol over $1 \mathrm{~min}$. A wavelength of $324 \mathrm{~nm}$ was used for detection of salen Mn complexes. Compound retention times in minutes were 12.9 (EUK-189), 12.8 (EUK-207), 10.9 (EUK-418), 11.9 (EUK-423), 11.5 (EUK-425), 11.2 (EUK-450), 10.0 (EUK-451), 10.8 (EUK-452), and 11.4 (EUK-453).

In vitro stability in SGF

To measure stability in USP SGF, compounds were diluted in SGF ( $34 \mathrm{mM} \mathrm{NaCl}, 3.2 \mathrm{mg} \mathrm{ml}^{-1}$ pepsin, $81.2 \mathrm{mM} \mathrm{HCl}$, $\mathrm{pH}$ approximately 1.2) and incubated at $37{ }^{\circ} \mathrm{C}$ for $90 \mathrm{~min}$ $(1 \mathrm{~h}$ is a standard gastric "transit time" according to the FDA) [36]. Aliquots were withdrawn, and intact compound was quantitated by HPLC-UV analysis as described earlier. 
Lipophilicity measurements

Lipophilicity was determined by vortexing a mixture of $400 \mu \mathrm{l} 500 \mu \mathrm{M}$ compound and $200 \mu \mathrm{l}$ octanol in a $1.7-\mathrm{ml}$ microfuge tube. The volumes and concentrations used differed from those used in previous methods [15] to optimize quantitation of the porphyrin compounds. Quantitation of the compound in each layer was performed by HPLC-UV analysis. Octanol partitioning coefficients $(P)$ were expressed as the ratio of the concentration of the sample in the octanol phase to that in the aqueous phase:

$P=\frac{[\mathrm{EUK}]_{\mathrm{oct}}}{[\mathrm{EUK}]_{\mathrm{aq}}}$

In vivo oral bioavailability

Aqueous solutions of compounds were administered to Sprague-Dawley rats, and blood samples were collected into vials pretreated with $\mathrm{Li}$ heparin at various time points for extraction and measurement of the compound by LCMS/MS. Details are given in the figure legends.

\section{Results}

Synthesis and catalytic activities

Seven EUK-400 series compounds were synthesized (Fig. 1a). Of these, EUK-418, EUK-423, and EUK-425 (originally compounds 3, 20, and 24, respectively) were described in the original patent [29], and the others were designed for this work. The design goals were to produce Mn porphyrin compounds bisubstituted with pharmacologically compatible substituents and having a range of predicted lipophilicities between those of EUK-418 and EUK-423. For comparison, the structures of the salen Mn complexes EUK-189 and EUK-207 [14] are shown in Fig. 1b. All EUK-400 series compounds exhibited significant SOD activities (Table 1), although these activities were lower than those of the salen Mn complexes. Although the assay methods differed, the SOD activities of the EUK-400 series compounds were comparable to that of AEOL11207, when normalized to that of $\mathrm{Cu} / \mathrm{Zn}$ SOD. (In other words, the EUK-400 compounds are 26- to 205-fold less active than $\mathrm{Cu} / \mathrm{Zn}$ SOD, whereas AEOL11207 is 123fold less active [27].) In addition, all EUK-400 series compounds had significant catalase and peroxidase activities (Table 1), although again at lower levels than those of EUK-189 and EUK-207.

Recent work has shown that MnTBAP in fact possesses no SOD activity [37]. Previously reported SOD activity was due to $\mathrm{Mn}$ aggregate impurities in commercial
Table 1 Catalytic activities of EUK-400 series compounds compared with those of EUK-189 and EUK-207

\begin{tabular}{lcll}
\hline Compound & $\mathrm{SOD} \mathrm{IC}_{50}(\mu \mathrm{M})$ & $\begin{array}{l}\mathrm{CAT} \\
\left(\mu \mathrm{M} \mathrm{H}_{2} \mathrm{O}_{2}\right. \\
\left.\mathrm{min}^{-1}\right)\end{array}$ & $\begin{array}{l}\text { POD } \\
(\mu \mathrm{M} \mathrm{TMB} \\
\left.\mathrm{min}^{-1}\right)\end{array}$ \\
\hline EUK-189 & 0.37 & $3.15 \pm 0.01$ & $3.61 \pm 0.05$ \\
EUK-207 & 0.48 & $3.21 \pm 0.04$ & $4.43 \pm 0.003$ \\
EUK-418 & 1.73 & $0.47 \pm 0.10$ & $0.63 \pm 0.08$ \\
EUK-423 & 6.36 & $0.45 \pm 0.18$ & $0.61 \pm 0.05$ \\
EUK-425 & 12.5 & $0.57 \pm 0.15$ & $0.58 \pm 0.03$ \\
EUK-450 & 6.39 & $0.58 \pm 0.08$ & $0.66 \pm 0.10$ \\
EUK-451 & 3.36 & $0.64 \pm 0.25$ & $0.59 \pm 0.023$ \\
EUK-452 & 11.6 & $0.54 \pm 0.06$ & $0.63 \pm 0.05$ \\
EUK-453 & 5.95 & $0.50 \pm 0.11$ & $0.56 \pm 0.03$ \\
\hline
\end{tabular}

Assays were performed as described in "Materials and methods." EUK-400 series compounds were tested from dimethyl sulfoxide stock solutions for superoxide dismutase $(S O D)$ and catalase $(C A T)$ activities, and from $\mathrm{H}_{2} \mathrm{O}$ for peroxidase (POD) activity. EUK-189 and EUK-207 were diluted from a $\mathrm{H}_{2} \mathrm{O}$ stock solution. Standard deviations of triplicate samples are given for CAT and POD. Under these conditions, $\mathrm{Cu} / \mathrm{Zn}$ SOD enzyme exhibited an $\mathrm{IC}_{50}$ value of $0.0011 \mu \mathrm{M}$

$T M B$ tetramethyl benzidine

preparations. To rule out the possibility that similar impurities in our preparations of EUK-400s are responsible for catalytic activity, we analyzed samples by ESI-MS. No peaks were observed at 341 or 381 (Fig. S1), which correspond to these Mn aggregates [37]. Since Mn clusters are sensitive to EDTA, whereas intact Mn porphyrins are not, we incubated the diluted compounds with EDTA, and found no change in activity. In addition, HPLC fractions of EUK-451 exhibited SOD and catalase activities only in the peak corresponding to intact compound (data not shown).

\section{Protection against STS-induced cell death in PC12 cells}

Previous studies have shown that salen Mn complexes protect cultured cortical neurons from STS-induced apoptosis and concomitantly inhibit intracellular oxidative stress [38]. In this study, we used the rat pheochromocytoma PC12 cell line, which is also sensitive to STS. Low doses of EUK-418, EUK-423, and EUK-451 protect PC12 cells against STS-induced cell death (Fig. 2). EUK-425, EUK-450, EUK-452, and EUK-453 were not significantly protective and were cytotoxic (data not shown). The salen Mn compounds EUK-189 and EUK-207 also show protection. Consistent with its greater stability [14], EUK-207 is more potent than EUK-189 in this model. Higher doses of EUK-400 compounds $(30-100 \mu \mathrm{M})$ are toxic in the absence of STS, whereas EUK-189 and EUK-207 were not toxic at any dose tested (data not shown). The biphasic dose-response curve for the EUK-400 compounds in Fig. 2 is consistent with this observed toxicity. 


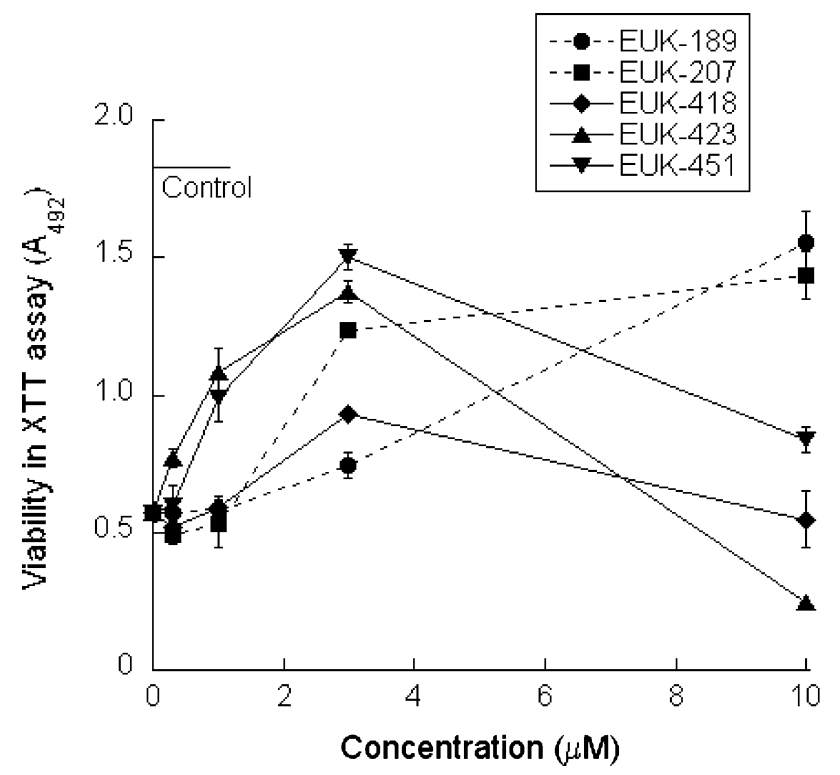

Fig. 2 Some EUK-400 series compounds protect PC12 cells against staurosporine (STS)-induced cell death. Rat pheochromocytoma (PC12) cells were cultured in collagen-coated 96-well plates and STS $(5 \mu \mathrm{M})$ was added to induce cell death. Test compounds were added together with the STS. After an 18-24-h incubation, test medium was removed, and cell viability was determined using the 2,3-bis(2-methoxy-4-nitro-5-sulfophenyl)-2 $\mathrm{H}$-tetrazolium-5-carboxanilide viability assay, as described in "Materials and methods." Control cells received no STS. In the absence of STS, the EUK-400 series compounds showed cytotoxicity at concentrations of 10 $30 \mu \mathrm{M}$. The data shown are direct comparisons of the compounds using means of duplicates, and error bars indicate the range. These data are representative of at least two additional independent tests of each compound in triplicate

In vitro "predictors" of oral availability

The purpose of these experiments was to conduct simple in vitro tests that others have used as potential predictors of oral availability. All EUK-400 series compounds are stable to incubation in SGF at $37{ }^{\circ} \mathrm{C}$ for 90 min (Table 2). This time period is longer than the gastric transit time, suggesting that degradation in the stomach is not a barrier to oral availability. In contrast, EUK-189 was much less stable, and EUK-207 had an intermediate stability that is consistent with its survival in the gastrointestinal system during the time period following oral ingestion. The EUK400 series compounds were originally designed for oral availability [29]. As discussed above, EUK-450, EUK-451, EUK-452, and EUK-453 were designed for this work as lipophilic variations of EUK-418 and EUK-423. Thus, octanol partitioning was performed as a measure of lipophilicity (Table 2). Besides its potential association with oral absorption, this test may also have some predictive value for the ability to cross membrane barriers such as the blood-brain barrier. With the exception of EUK-451, all of the EUK-400 series compounds are substantially more
Table 2 Simulated gastric fluid $(S G F)$ stability and octanol partitioning

\begin{tabular}{lclc}
\hline Compound & SGF stability $(\%)$ & $P$ & $\log _{10} P$ \\
\hline EUK-189 & 14 & $0.13 \pm 0.00$ & $-0.90 \pm 0.013$ \\
EUK-207 & 72 & $0.04 \pm 0.01$ & $-1.41 \pm 0.15$ \\
EUK-418 & 92 & $3.53 \pm 0.14$ & $0.548 \pm 0.009$ \\
EUK-423 & 91 & $8.07 \pm 0.10$ & $0.907 \pm 0.002$ \\
EUK-425 & 97 & $8.56 \pm 0.35$ & $0.932 \pm 0.006$ \\
EUK-450 & 98 & $4.46 \pm 0.11$ & $0.650 \pm 0.010$ \\
EUK-451 & 100 & $0.22 \pm 0.01$ & $-0.660 \pm 0.011$ \\
EUK-452 & 98 & $94.0 \pm 1.7$ & $1.973 \pm 0.008$ \\
EUK-453 & 98 & $4.16 \pm 0.16$ & $0.619 \pm 0.017$ \\
\hline
\end{tabular}

EUK compounds were incubated with SGF for $90 \mathrm{~min}$ at $37^{\circ} \mathrm{C}$. Intact compound was quantitated by high-performance liquid chromatography (HPLC). Octanol partitioning was performed as described in "Materials and methods," except for EUK-207, for which the volumes and concentrations were as described in [15]. The compound in octanol and aqueous phases was quantitated by HPLC, and standard deviations of triplicate samples are given

lipophilic than EUK-189 or EUK-207, two salen Mn complexes that have no oral bioavailability. EUK-452 was the most lipophilic, with a $\log _{10} P$ value of 1.98 ; a value of 2 or greater may predict the ability to cross the blood-brain barrier [39]. Another commonly used in vitro model for oral availability is permeability through a Caco- 2 monolayer [40-42]. We found that this model system was not useful for the EUK-400 series compounds, because they stuck to the cellular layer, so we proceeded to test the compounds in vivo.

In vivo oral availability

One compound, EUK-425, was selected for a bioavailability study comparing the pharmacokinetics of oral versus intravenous routes of administration. When EUK425 was administered to rats by oral gavage and intravenous injection, the compound was detected in plasma by LC-MS/MS (Fig. 3). Plasma levels dropped over the first hour after intravenous administration, whereas they remained relatively constant after administration by oral gavage. Subsequently all EUK-400 series compounds were administered to rats by oral gavage, and the plasma was found to contain a sustained level of the compound at time points up to $6 \mathrm{~h}$ (Table 3). Plasma levels of each compound in each individual rat, averaged to produce the data in Table 3, are shown in Table S2. Thus, all compounds tested are orally available in rats. Our intent was not to rank the compounds with respect to their oral bioavailability, but to simply screen them in vivo to demonstrate whether they could be delivered orally. Consequently, each analog was administered at the most 


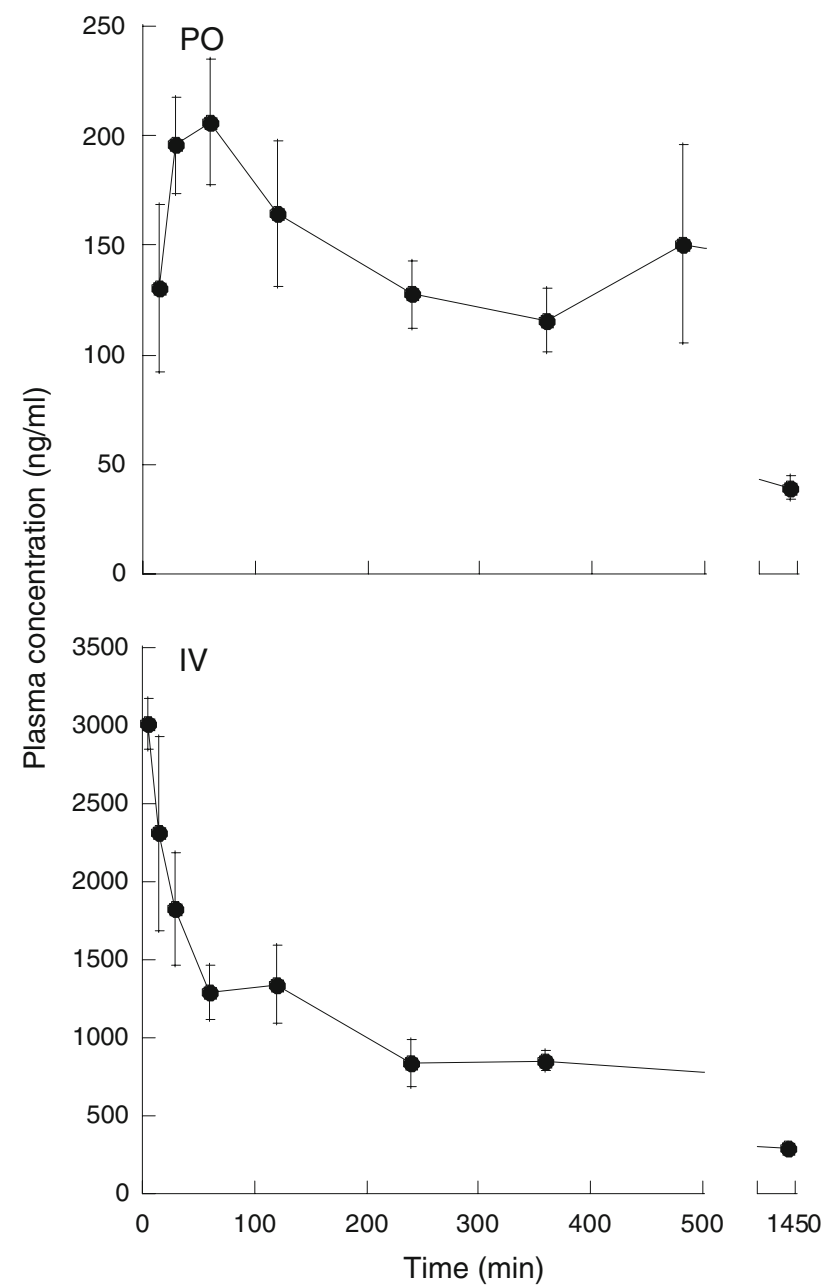

Fig. 3 In vivo oral availability of EUK-425 in rats. EUK-425 was administered to Sprague-Dawley rats $(n=3)$ by intragastric gavage $(P O)$ or intravenous injection $(I V)$. The compound was formulated in dimethyl sulfoxide/Solutol HS 15/phosphate-buffered saline, $\mathrm{pH} 7.4$ (5:5:90, by volume), and the doses were $5 \mathrm{mg} \mathrm{kg}^{-1}$ for PO and $1 \mathrm{mg} \mathrm{kg}^{-1}$ for IV administration. The final volumes administered were 1.35-1.53 ml. Plasma was collected from a jugular vein catheter at various time points, and quantitation of compounds was performed by liquid chromatography with tandem mass spectroscopy. Fifty microliters of plasma was precipitated with $200 \mu \mathrm{l}$ acetonitrile, and the supernatant was analyzed using a TSQ Quantum machine. Tenmicroliter aliquots were injected for analysis. The high performance liquid chromatography column was Synergi Fusion-RP 80, $4 \mu \mathrm{m}$ $(2 \mathrm{~mm} \times 50 \mathrm{~mm})$. The runs were performed at a flow rate of $0.5 \mathrm{ml} \mathrm{min}{ }^{-1}$ with mobile phase A consisting of $13.3 \mathrm{mM}$ ammonium formate, $6.7 \mathrm{mM}$ formic acid in water. Mobile phase B was $6 \mathrm{mM}$ ammonium formate, $3 \mathrm{mM}$ formic acid in water/acetonitrile $(1: 9 \mathrm{v} / \mathrm{v})$. The gradient was $20-100 \%$ mobile phase B over $2.5 \mathrm{~min}$. The apparent molecular ion for EUK-425 was 516.0 $\mathrm{m} / \mathrm{z} \rightarrow 475.2 \mathrm{~m} / \mathrm{z}$

convenient dose on the basis of factors such as solubility. Under similar conditions, with oral doses as high as $50 \mathrm{mg} \mathrm{kg}{ }^{-1}$, EUK-189 and EUK-207 are undetectable in plasma (data not shown).

\section{Discussion}

Overall, the EUK-400 compounds exhibit biological properties consistent with their potential value as therapeutic agents, including scavenging of ROS and cytoprotective activities. In this respect, these low molecular weight Mn porphyrins share some similarities to the salen Mn complexes but, in addition, they show oral bioavailability, as hypothesized. To facilitate discussion of comparisons among the compounds, Table 4 summarizes their relative properties.

EUK-400s are SOD/catalase mimetics with peroxidase activity

As many metalloporphyrins have been demonstrated to neutralize ROS, we tested the EUK-400 series compounds for antioxidant activity. Relative to the salen Mn complexes [4], the EUK-400 series compounds have lower SOD, catalase, and peroxidase activities (Table 1). Among the EUK-400 series, the compounds have similar catalase and peroxidase activities; however, their SOD activities vary about tenfold from the most active (EUK-418) to the least active (EUK-425). These results contrast with the structure-activity relationship we have reported for a series of salen Mn complexes, which have similar SOD activities, but varying catalase and peroxidase activities [4]. Because of the lack of any obvious trends and the limited number of EUK-400 series compounds examined, no strong structureactivity relationships can be established, but that was not the intent of this study. Nonetheless, we speculate that differences in SOD activity may in part be related to steric differences among the compounds. For example, EUK-418 with its two cyclopropyl groups has an almost fivefold greater SOD activity than EUK-453 with its two linear propyl chains, and might be expected to have a less planar (more "ruffled") structure owing to the bulkier cyclopropyl groups at two of its meso positions [43]. This in turn should affect the coordination of $\mathrm{Mn}$ in relation to the porphyrin, potentially favoring SOD catalytic activity [37, 44]. For the compounds with cycloalkyl groups at the meso positions, the SOD activity seems to be inversely related to the steric bulk of these substituents. The ${ }^{1} \mathrm{H}-\mathrm{NMR}$ spectra of the unmetallated precursors to these compounds confirm that the relative steric interactions are EUK-452 > EUK$451>$ EUK-418 (less planar to most planar/free spinning). The $\beta$ protons closest to the cycloalkyl groups are broadened in the 5,15-dicyclohexyl porphyrin, less broadened in the 5,15-ditetrahydropyranoporphryin, and not broadened at all in 5,15-dicyclopropyl porphyrin. Other factors such as electronics and lipophilicity may also affect SOD activity, and studying a broader series of compounds might provide evidence to address such speculations. For 
Table 3 In vivo oral availability of EUK-400 series compounds in rats

\begin{tabular}{|c|c|c|c|c|c|c|}
\hline \multirow[t]{2}{*}{ Compound } & \multirow[t]{2}{*}{ Dose $\left(\mathrm{mg} \mathrm{kg}^{-1}\right)$} & \multicolumn{5}{|c|}{ Plasma concentration $\left(\mathrm{ng} \mathrm{ml}^{-1}\right)$} \\
\hline & & $30 \mathrm{~min}$ & $60 \mathrm{~min}$ & $120 \mathrm{~min}$ & $240 \mathrm{~min}$ & $360 \mathrm{~min}$ \\
\hline EUK-418 & 0.96 & $128 \pm 83$ & $250 \pm 147$ & $245 \pm 145$ & $299 \pm 224$ & $259 \pm 166$ \\
\hline EUK-423 & 0.52 & $25 \pm 7$ & $53 \pm 19$ & $48 \pm 23$ & $110 \pm 61$ & $118 \pm 17$ \\
\hline EUK-425 & 1.7 & $52 \pm 19$ & $48 \pm 21$ & $78 \pm 47$ & $96 \pm 20$ & $113 \pm 15$ \\
\hline EUK-450 & 2.7 & $11 \pm 10$ & $15 \pm 9$ & $48 \pm 46$ & $53 \pm 53$ & $47 \pm 38$ \\
\hline EUK-451 & 0.93 & $44 \pm 38$ & $61 \pm 54$ & $66 \pm 62$ & $107 \pm 102$ & $86 \pm 70$ \\
\hline EUK-452 & 1.6 & $57 \pm 50$ & $52 \pm 42$ & $75 \pm 63$ & $75 \pm 76$ & $71 \pm 63$ \\
\hline EUK-453 & 0.23 & $8.8 \pm 5.9$ & $8.1 \pm 5.5$ & $7.7 \pm 6.1$ & $7.7 \pm 6.0$ & $4.6 \pm 4.2$ \\
\hline
\end{tabular}

EUK-400 compounds (formulated in $0.3 \mathrm{~g} \mathrm{ml}^{-1}$ sodium cholate in a final volume of 1.0-1.5 ml) were administered by intragastric gavage to Sprague-Dawley rats in quadruplicate $(n=3$ for EUK-450). Plasma was collected by orbital bleeding at various time points, and quantitation of compounds was performed by liquid chromatography with tandem mass spectroscopy (LC-MS/MS). Vials were centrifuged to separate the plasma. Plasma was transferred to fresh vials and chilled in ice before freezing it at $-80{ }^{\circ} \mathrm{C}$. Extraction and protein precipitation were done in the same step by adding $40 \mu \mathrm{l}$ of thawed plasma sample to $1.5 \mathrm{ml}$ of LC-MS/MS mobile phase ( $3 \mathrm{mM}$ ammonium acetate, $0.065 \%$ formic acid, $33.2 \%$ acetonitrile, $33.2 \%$ methanol) and mixing well. After centrifugation, $50 \mu \mathrm{l}$ of the supernatant was injected for analysis. A Waters model 2690 HPLC system was used with a Whatman Partisil 10 ODS-3 column $(4.6 \mathrm{~mm} \times 100 \mathrm{~mm})$, followed by a Quattro LC instrument manufactured by Micromass. The runs were performed isocratically at a flow rate of $0.5 \mathrm{ml} \mathrm{min}{ }^{-1}$ with a mobile phase of $3 \mathrm{mM}$ ammonium acetate, $0.065 \%$ formic acid, $33.2 \%$ acetonitrile, and $33.2 \%$ methanol. EUK- 425 and EUK-452 required a mobile phase of $3 \mathrm{mM}$ ammonium acetate, $0.065 \%$ formic acid, $36 \%$ acetonitrile, and $36 \%$ methanol. Four multiple reaction monitoring transitions were monitored for each compound (see the electronic supplementary material). The following transitions were used for quantitation: for EUK-418, $484.11 \mathrm{~m} / \mathrm{z} \rightarrow 442.80 \mathrm{~m} / \mathrm{z}$; for EUK423, $556.20 \mathrm{~m} / z \rightarrow 514.93 \mathrm{~m} / z$; for EUK-425, $475.21 \mathrm{~m} / \mathrm{z} \rightarrow 430.02 \mathrm{~m} / \mathrm{z}$; for EUK-450, $634.95 \mathrm{~m} / \mathrm{z} \rightarrow 618.77 \mathrm{~m} / \mathrm{z}$; for EUK-451, $571.95 \mathrm{~m} /$ $z \rightarrow 530.84 \mathrm{~m} / z$; for EUK-452, $527.05 \mathrm{~m} / \mathrm{z} \rightarrow 399.77 \mathrm{~m} / \mathrm{z}$; for EUK-453, $488.07 \mathrm{~m} / \mathrm{z} \rightarrow 446.94 \mathrm{~m} / \mathrm{z}$. Standard curves for this study had the most useful quantitation range of 4.5-7,600 ng ml${ }^{-1}$, although the limits of detection were even lower for many of the compounds. Under similar conditions, EUK-189 and EUK-207, which can be quantitated with similar sensitivity, are undetectable in plasma after oral administration of up to $50 \mathrm{mg} \mathrm{kg}^{-1}$, although they are readily detectable when given by injection (data not shown)

Table 4 Summary of properties of EUK compounds

\begin{tabular}{lllllllll}
\hline Compound & SOD & CAT & POD & PC12 & TOX & LIP & SGF & ORAL \\
\hline EUK-189 & 1 & ++ & ++ & + & - & 8 & - & - \\
EUK-207 & 1 & ++ & ++ & ++ & - & 9 & + & - \\
EUK-418 & 2 & + & + & + & ++ & 6 & ++ & + \\
EUK-423 & 4 & + & + & +++ & + & 3 & ++ & + \\
EUK-425 & 5 & + & + & - & ++ & 2 & +++ & + \\
EUK-450 & 4 & + & + & - & ++ & 4 & +++ & + \\
EUK-451 & 3 & + & + & +++ & + & 7 & +++ & + \\
EUK-452 & 5 & + & + & - & ++ & 1 & +++ & + \\
EUK-453 & 4 & + & + & - & ++ & 5 & +++ & +
\end{tabular}

Data described elsewhere in the paper are summarized here to facilitate comparison among compounds. For lipophilicity $(L I P)$, compounds are ranked with respect to their octanol partitioning coefficients (Table 2), with 1 being most lipophilic. For SOD activity (Table 1), compounds are assigned scores from 1 (highest activity) to 5 (lowest activity). For the other parameters, + and - scores are used to enable semiquantitative comparisons among compounds. $C A T$ and $P O D$ are CAT and POD activities (Table 1), respectively. PC12 represents cytoprotective activity at lower, less toxic doses (less than $4 \mu \mathrm{M}$; Fig. 2), so is an indicator of relative potency. TOX represents cytotoxic activity in PC12 cells (Fig. 2), as well as capillary endothelial cells [23], at higher doses (more than $10 \mu \mathrm{M}$ ). $S G F$ is the stability in SGF (Table 2), and ORAL represents whether or not the compound, administered orally at up to $50 \mathrm{mg} \mathrm{kg}^{-1}$, is orally available in rats (Fig. 3, Table 3) example, with a larger group of compounds one could vary separately the solubility, electronics, and steric bulk at the meso position of the porphyrin to see if any logical trends based on these factors develop.

It is interesting to note that, in contrast to many biologically active Mn porphyrins previously reported in the literature, all the EUK-400 series compounds except EUK425 have two unsubstituted meso positions. In fact, Trova et al. [31] reported that many Mn porphyrins having two unsubstituted meso positions have greater catalase activity and greater inhibition of lipid peroxidation than other MnTBAP analogs.

Some EUK-400s protect PC12 cells against cell death induced by STS

There was no close correlation between SOD or catalase activity of these compounds and their ability to protect PC12 cells against apoptosis. We would not have expected a close association because of the complexity of the cellular model as compared with the individual catalytic activity assays. Similarly, the ROS scavenging properties of a series of salen Mn complexes did not directly predict their relative activities in cell culture or in vivo [4]. In the current circumstance, all 
the EUK-400 compounds are cytotoxic at certain doses, and this property most certainly influences their relative activities in an assay for cytoprotection. In the PC12 assay, EUK423 and EUK-451 were the most protective of the seven Mn porphyrins tested, although both showed biphasic dose curves consistent with their cytotoxicity. Although they both had relatively high SOD activities, this property alone was not sufficient. EUK-418, the compound with the highest SOD activity, was a relatively poor protector in the PC12 model, most likely owing to its greater toxicity (Table 4). Similarly, in an endothelial cell culture model, we showed that EUK-418 and EUK-423, as well as EUK-189 and EUK207, mitigated apoptosis induced by ionizing radiation, with EUK-418 showing the greatest cytotoxicity of the four, EUK-423 showing intermediate toxicity, and the salen Mn complexes showing no detectable toxicity [23]. We subsequently demonstrated that EUK-451 was also a potent mitigator in this model, and had significantly lower cytotoxicity than the other EUK-400 compounds (unpublished data). Four compounds, EUK-450, EUK-452, EUK-453, and EUK-425, were the most cytotoxic and, not surprisingly, showed no cytoprotective activity against STS-induced apoptosis. Overall, the cytotoxicity of the EUK-400 series compounds strongly influences observed cytoprotection. Highly protective, less toxic compounds are favored in this or in any other cellular model. Such differences will not be evident, of course, in an SOD or catalase activity assay. For this and other reasons, direct associations between such specific ROS scavenging activities and cytoprotective activity would not be predicted. Furthermore, no cellular model will absolutely predict relative activity and toxicity in vivo [4]. In addition, mechanisms other than ROS scavenging activity may also contribute to the cytoprotective activity of the EUK-400 series compounds in a given model (see below). Previous work with salen Mn complexes has shown that other properties, such as intracellular accessibility and stability, are at least as important as catalytic activity in predicting cytoprotective activity [4, 38]. Consistent with these findings, EUK-207 is more protective than EUK-189 in the PC12 assay (Fig. 2), although these compounds have similar catalytic activities (Table 1). Although cytotoxicity is not an issue with these two analogs at the concentrations tested, we previously showed that a salen Mn complex with very high catalase activity, EUK-178, showed cytotoxicity in cell culture as well as poor activity in vivo [4].

It is extremely interesting that, despite their lower SOD and other ROS scavenging activities, EUK-451 and EUK423 protected PC12 cells at lower concentrations than did the salen $\mathrm{Mn}$ complexes. This greater apparent potency may very well be related to enhanced intracellular stability since the Mn porphyrins are inherently more stable than the salen Mn complexes as evidenced, for example, in the SGF stability studies. In addition, it is quite possible that Mn porphyrins have more complex mechanisms of cytoprotection than salen Mn complexes (see the discussion later).

In general, it is clear from these and our previous findings that in vitro ROS scavenging activity is unlikely to directly predict activity in cellular models. Consistent with this, others have shown that the in vitro catalytic activities of various ROS scavengers do not correlate with survival of retinal ganglion cells [45]. Again, this finding is not at all surprising given the potential complexity of any cytoprotection assay. Similar to our observations in the ionizing radiation studies cited above, Fig. 2 shows that the salen Mn complexes do not display the dose-limiting cytotoxicity seen in vitro with the EUK-400 series compounds. Although it is promising that no toxicity was observed in the in vivo oral availability studies reported here (Fig. 3, Table 3), no formal toxicity studies have yet been done with the EUK-400 compounds. Further studies using various relevant in vivo models will eventually help to predict the best candidate(s) for potential therapeutic use. Indeed, bioavailability properties will play a key role in this selection.

SGF and octanol partitioning are useful, but insufficient predictors of oral bioavailability

We performed these tests because others have found them helpful in predicting oral availability. Unfortunately, transport across Caco-2 cell monolayers was an unsuitable model system for these compounds owing to their sticking to the cell layer. Not surprisingly, octanol partitioning data alone do not correlate with oral bioavailability. EUK-189 and EUK-451 have similar $P$ values (Table 2); however, EUK-451 is orally bioavailable, whereas EUK-189 is not. The EUK-400 series compounds exhibited a wide range of partitioning coefficients, and all exhibited oral availability. It is possible that a common mechanism operates to transport these porphyrins into the bloodstream; an intestinal heme transporter has been identified [46]. Once in the bloodstream, EUK-400s may bind to serum albumin, as do other porphyrins [47], and as we have observed in vitro with EUK-418, EUK-423, and EUK-425 (data not shown). Stability in SGF is necessary, but not sufficient to predict oral availability. For example, EUK-207 has sufficient stability in SGF on the basis of gastric transit time, yet it is not orally bioavailable. On the basis of its structure, one would not expect EUK-207 to be recognized by a heme transporter.

In vivo oral availability in rats

Previous work [29] showed that EUK-418 is orally bioavailable in mice, and this compound was detected in selected tissues (kidney $>$ liver $>$ lung $\gg$ brain). The 
present work compares the plasma levels of one compound, EUK-425, when administered orally and intravenously (Fig. 3) and also demonstrates the oral availability of all EUK-400 series compounds (Table 3). As yet, the tissue distribution of orally administered EUK-400 compounds in rats is unknown. Given that ROS are implicated in neurodegeneration, it is of great interest to learn if any of these compounds pass through the blood-brain barrier. AEOL11207, another lipophilic metalloporphyrin, was shown to be present in the brain tissue of mice after subcutaneous or oral administration [27]. It is possible that different analogs will be appropriate for different target tissues. Our future in vivo studies will include investigation of this question.

\section{Speculation on mechanism of action}

The conventional thinking is that SOD/catalase mimetics protect against oxidative stress by neutralizing ROS in vivo, and EUK-400 series compounds may also act by this mechanism. According to a recent paper by Abramov et al. [48], neurons exposed to anoxia and reperfusion exhibit at least three different mechanisms of ROS generation: an initial mitochondrial burst, a delayed xanthine oxidase mediated production, and an NADPH oxidase dependent production upon reoxygenation. Thus, different SOD mimetics may have different site(s) of action, depending on their subcellular localization. Since the EUK compounds exhibit a wide range of partition coefficients (Table 2), they might be expected to migrate into different subcellular compartments. Schlieve et al. [45] recently found a lack of correlation between the activities of ROS scavengers, including manganese(III) tetrakis(1-methyl-4-pyridyl) porphyrin (MnTMPyP), in cell-free catalytic assays and in cultured retinal ganglion cells, consistent with other findings that catalytic activity in vitro does not correlate to cytoprotection in vivo.

As noted above, the EUK-400 series compounds protect cells at lower concentrations than the salen Mn complexes EUK-189 and EUK-207, even though their catalytic activities are lower. Besides their potential for greater intracellular stability (see Table 2), it is also possible that EUK-400 series compounds act via an additional or alternative mechanism which does not involve ROS. Other groups have proposed alternative mechanisms of action for Mn porphyrins. MnTBAP inhibits nuclear translocation of apoptosis-inducing factor [49] and $N$-methyl D-aspartate receptor mediated increases in intracellular $\mathrm{Ca}^{2+}$ levels [50]. Iron tetrakis(4-benzoic acid) porphyrin and cobalt tetrakis(4-benzoic acid) porphyrin increase expression of heme oxygenase-1 [51], an effect which correlates with the protection of cardiomyocytes against apoptosis by doxorubicin [52]. MnTMPyP scavenges NO and inhibits soluble guanylyl cyclase activity [53]. It also inhibits the activity of purified NO synthase by interfering with its reductase domain [53]. Another possible antiapoptotic mechanism which we have recently considered is inhibition of the mitochondrial permeability transition. Protoporphyrin IX binds to the peripheral benzodiazepam receptor (PBR) [54] and participates in the induction of the mitochondrial permeability transition [55]. Other PBR ligands inhibit apoptosis [56, 57]. Preliminary data show that some of these compounds have affinity for the PBR [58], although the physiological implications are as yet unknown. The complexity of the mechanisms by which these and similar compounds exert their cytoprotective properties is an avenue for much future research.

Therapeutic potential

Other Mn porphyrins have been proposed as possible therapeutics for various medical conditions. As described in "Introduction," Mn porphyrins and salen Mn provide neuroprotection in many disease models in vivo. Clinical trials are now under way for manganese(III) tetrakis $\left(\mathrm{N}, \mathrm{N}^{\prime}-\right.$ diethylimidazolium-2-yl) porphyrin (AEOL10150), an injectable Mn porphyrin, for treatment of ALS [59]. In addition to their therapeutic potential in diseases of the CNS, SOD/catalase mimetics should be effective in treating peripheral diseases such as diabetes [60] and heart disease [61]. Recent studies have also suggested a role for salen $\mathrm{Mn}$ complexes and $\mathrm{Mn}$ porphyrins as medical countermeasures against radiation injury $[16,17,18,19$, $22,23]$. Oral bioavailability is a useful property for a subset of these therapeutic indications, whereas an injectable or sustained-release formulation will be appropriate for others.

In summary, we analyzed EUK-418 and several new analogs. These compounds, called the "EUK-400 series," are SOD and catalase mimetics, some of which protect cultured cells from STS-induced cell death. Unlike the salen Mn complexes such as EUK-189 and EUK-207, the EUK-400 series compounds are detected in plasma after oral administration. Thus, they are potential orally administered therapeutics for diseases in which oxidative stress is involved as well as injuries caused by radiation exposure.

Acknowledgments We acknowledge Bernard Meunier and Frederic Cosledan, who designed and synthesized EUK-418, EUK-423, and EUK-425 [29] with support from and collaboration with B.M.C., K.D.H., and S.R.D., formerly at Eukarion. The authors thank Myra Robinson for able technical assistance and Alexander Lazarev for helpful discussions. This work was supported by a subcontract (S.R.D., principal investigator) under grant no. U19-A1067734 to the Medical College of Wisconsin (John E. Moulder, principal investigator) and a Pilot Grant (R.A.R., principal investigator) awarded by the Centers for Medical Countermeasures Against Radiation (CMCR) 
program at the Medical College of Wisconsin. The CMCR program is funded by the NIAID.

Open Access This article is distributed under the terms of the Creative Commons Attribution Noncommercial License which permits any noncommercial use, distribution, and reproduction in any medium, provided the original author(s) and source are credited.

\section{References}

1. Robbins MEC, Zhao W (2004) In J Radiat Biol 80:251-259

2. Reynolds A, Laurie C, Lee Mosley R, Gendelman HE (2007) Int Rev Neurobiol 82:297-325

3. Halliwell B, Gutteridge JMC (1999) Free radicals in biology and medicine. Oxford University Press, Oxford

4. Doctrow SR, Huffman K, Marcus CB, Tocco G, Malfroy E, Adinolfi CA, Kruk H, Baker K, Lazarowych N, Mascarenhas J, Malfroy B (2002) J Med Chem 45:4549-4558

5. Faulkner KM, Liochev SI, Fridovich I (1994) J Biol Chem 269:23471-23476

6. Day BJ, Fridovich I, Crapo JD (1997) Arch Biochem Biophys 347:256-262

7. Crow JP (2000) Free Radic Biol Med 28:1487-1494

8. Shimanovich R, Hannah S, Lynch V, Gerasimchuk N, Mody TD, Magda D, Sessler J, Groves JT (2001) J Am Chem Soc 123:3613-3614

9. Sharpe MA, Ollosson R, Stewart VC, Clark JB (2002) Biochem J 366:97-107

10. Peng J, Stevenson FF, Doctrow SR, Andersen JK (2005) J Biol Chem 280:29194-29198

11. Jung C, Rong Y, Doctrow S, Baudry M, Malfroy B, Xu Z (2001) Neurosci Lett 304:157-160

12. Melov S, Wolf N, Strozyk D, Doctrow SR, Bush AI (2005) Free Radic Biol Med 38:258-261

13. Baker K, Bucay-Marcus C, Huffman C, Kruk H, Malfroy B, Doctrow SR (1998) J Pharmacol Exp Ther 284:215-221

14. Liu R, Liu IY, Bi X, Thompson RF, Doctrow SR, Malfroy B, Baudry M (2003) Proc Natl Acad Sci USA 100:8526-8531

15. Melov S, Doctrow SR, Schneider JA, Haberson J, Patel M, Coskun PE, Huffman K, Wallace DC, Malfroy B (2001) J Neurosci 21:8348-8353

16. Langan AR, Khan MA, Yeung IW, Van Dyk J, Hill RP (2006) Radiother Oncol 79:231-238

17. Srinivasan V, Doctrow S, Singh VK, Whitnall MH (2008) Immunopharmacol Immunotoxicol 30:271-290

18. Gauter-Fleckenstein B, Fleckenstein K, Owzar K, Jiang C, Batinic-Haberle I, Vujaskovic Z (2008) Free Radic Biol Med 44:982-989

19. Vujaskovic Z, Batinic-Haberle I, Rabbani ZN, Feng QF, Kang SK, Spasojevic I, Samulski TV, Fridovich I, Dewhirst MW, Anscher MS (2002) Free Radic Biol Med 33:857-863

20. Patel M, Day BJ (1999) Trends Pharmacol Sci 20:359-364

21. Lee JH, Lee YM, Park JW (2005) Biochem Biophys Res Commun 334:298-305

22. Rabbani ZN, Batinic-Haberle I, Anscher MS, Huang J, Day BJ, Alexander E, Dewhirst MW, Vujaskovic Z (2007) Int J Radiat Oncol Biol Phys 67:573-580

23. Rosenthal RA, Vorotnikova E, Fisette L, Braunhut S, Huffman K, Tries M, Doctrow SR (2006) Free Radic Biol Med 41:S159-S160

24. Crow JP, Calingasan NY, Chen J, Hill JL, Beal MF (2005) Ann Neurol 58:258-265

25. Sharma SS, Gupta S (2007) Eur J Pharmacol 561:72-79
26. Mackensen GB, Patel M, Sheng H, Calvi CL, Batinic-Haberle I, Day BJ, Liang LP, Fridovich I, Crapo JD, Pearlstein RD, Warner DS (2001) J Neurosci 21:4582-4592

27. Liang LP, Huang J, Fulton R, Day BJ, Patel M (2007) J Neurosci 27:4326-4333

28. Rosenthal RA, Fisette LW, Huffman K, Damphousse CA, Callaway WB, Malfroy B, Doctrow S (2007) Free Radic Biol Med 43:S188-S189

29. Meunier B, Cosledan F (2006) Office UPaT, 20060241095, 26 October 2006

30. Lahaye D, Muthukumaran K, Hung CH, Gryko D, Reboucas JS, Spasojevic I, Batinic-Haberle I, Lindsey JS (2007) Bioorg Med Chem 15:7066-7086

31. Trova MP, Gauuan PJ, Pechulis AD, Bubb SM, Bocckino SB, Crapo JD, Day BJ (2003) Bioorg Med Chem 11:2695-2707

32. Littler BJ, Miller MA, Hung CH, Wagner RW, O'Shea DF, Boyle PD, Lindsey JS (1999) J Org Chem 64:1391-1396

33. Falk JE, Smith KM (eds) (1975) Porphyrins and metalloporphyrins. Elsevier, New York

34. Neya S, Funasaki N (1997) J Heterocycl Chem 34:689-690

35. Giblin GMP, Box PC, Campbell IB, Hancock AP, Roomans S, Mills GI, Molloy C, Tranter GE, Walker AL, Doctrow SR, Huffman K, Malfroy B (2001) Bioorg Med Chem Lett 11:1367-1370

36. FDA (2000) Waiver of in vivo bioavailability and bioequivalence studies for immediate-release solid oral dosage forms based on a biopharmaceutics classification system. http://www.fda.gov/Cder/ guidance/3618fnl.htm

37. Reboucas JS, Spasojevic I, Batinic-Haberle I (2008) J Biol Inorg Chem 13:289-302

38. Pong K, Doctrow SR, Huffman K, Adinolfi CA, Baudry M (2001) Exp Neurol 171:84-97

39. Hansch C, Bjorkroth JP, Leo A (1987) J Pharm Sci 76:663-687

40. Gres MC, Julian B, Bourrie M, Meunier V, Roques C, Berger M, Boulenc X, Berger Y, Fabre G (1998) Pharm Res 15:726-733

41. Yee S (1997) Pharm Res 14:763-766

42. Stoner CL, Cleton A, Johnson K, Oh DM, Hallak H, Brodfuehrer J, Surendran N, Hans HK (2004) Int J Pharm 269:241-249

43. Song Y, Haddad RE, Jia SL, Hok S, Olmstead MM, Nurco DJ, Schore NE, Zhang J, Ma JG, Smith KM, Gazeau S, Pecaut J, Marchon JC, Medforth CJ, Shelnutt JA (2005) J Am Chem Soc 127:1179-1192

44. Reboucas JS, Spasojevic I, Tjahjono DH, Richaud A, Mendez F, Benov L, Batinic-Haberle I (2008) Dalton Trans 1233-1242

45. Schlieve CR, Lieven CJ, Levin LA (2006) Invest Ophthalmol Vis Sci 47:3878-3886

46. Shayeghi M, Latunde-Dada GO, Oakhill JS, Laftah AH, Takeuchi K, Halliday N, Khan Y, Warley A, McCann FE, Hider RC, Frazer DM, Anderson GJ, Vulpe CD, Simpson RJ, McKie AT (2005) Cell 122:789-801

47. Cohen S, Margalit R (1990) Biochem J 270:325-330

48. Abramov AY, Scorziello A, Duchen MR (2007) J Neurosci 27:1129-1138

49. Lee BI, Chan PH, Kim GW (2005) Stroke 36:2712-2717

50. Tauskela JS, Brunette E, O'Reilly N, Mealing G, Comas T, Gendron TF, Monette R, Morley P (2005) FASEB J 19:17341736

51. Shan Y, Pepe J, Lu TH, Elbirt KK, Lambrecht RW, Bonkovsky HL (2000) Arch Biochem Biophys 380:219-227

52. Konorev EA, Kotamraju S, Zhao H, Kalivendi S, Joseph J, Kalyanaraman B (2002) Free Radic Biol Med 33:988

53. Pfeiffer S, Schrammel A, Koesling D, Schmidt K, Mayer B (1998) Mol Pharmacol 53:795-800

54. Verma A, Nye JS, Snyder SH (1987) Proc Natl Acad Sci USA $84: 2256-2260$

55. Pastorino JG, Simbula G, Gilfor E, Hoek JB, Farber JL (1994) J Biol Chem 269:31041-31046 
56. Bono F, Lamarche I, Prabonnaud V, Le Fur G, Herbert JM (1999) Biochem Biophys Res Commun 265:457-461

57. Leducq N, Bono F, Sulpice T, Vin V, Janiak P, Fur GL, O'Connor SE, Herbert JM (2003) J Pharmacol Exp Ther 306:828-837

58. Malfroy-Camine B, Doctrow S (2008) Application UP, 2008 033444, 20 March 2008
59. Orrell RW (2006) Curr Opin Investig Drugs 7:70-80

60. Piganelli JD, Flores SC, Cruz C, Koepp J, Batinic-Haberle I, Crapo J, Day B, Kachadourian R, Young R, Bradley B, Haskins K (2002) Diabetes 51:347-355

61. Lubbers NL, Polakowski JS, Crapo JD, Wegner CD, Cox BF (2003) J Cardiovasc Pharmacol 41:714-719 